\title{
Perekrutan Praktisi Hubungan Masyarakat dalam Kajian Teori Feminis dan Velvet Ghetto
}

\author{
Deborah N. Simorangkir \\ Swiss German University \\ deborah.simorangkir@sgu.ac.id
}

\begin{abstract}
One main issue found in gender research studies on public relations is the small number of women who hold a leadership role. However, this fact does not only apply to the public relations inudstry, but almost all industries. The purpose of this article is to analyze the prblem within the recruitment process of $P R$ practitioners from the point of view of the senior practitioners. In order to achieve this, focus group discussions were conducted with senior $P R$ practitioners who are members of a PR professional association. Data gatheredwere analyzed from the perspective of feminist theories and The Velvet Ghetto. Based on the discussions, two conclusions were made. First, That the public relations profession is an 'open profession', which means that it should be open for, a) men and women, b) all ages, c) all backgrounds and disciplines. Second, that statistically and universally, a) PR education appears to be more attractive to women compared to men, $b)$ overall, there are more female PR practitioners than males, however, $c$ ) at the senior, top management positions in large companies, beit national or international, male practitioners are dominant. The researcher concludes that there needs to be an attempt to increase the status of the PR profession in the society, and strive to achieve gender equity in reaching top management. The researcher suggests for colaborations to be held between three parties, namely: Higher education institutions, professional associations, and industries. Such colaborations can be in the form of mentorships between a beginner and a manager; career counselling; and workshops. Companies are also advised to establish policies, e.g. flextime, and offer facilities, e.g., daycares, that would enable women to pursue a career.
\end{abstract}

Keywords: Public Relations, feminist theory, velvet ghetto

\begin{abstract}
Abstrak
Salah satu pokok permasalahan yang ditemukan dalam studi gender humas adalah sedikitnya perempuan yang memegang peran kepemimpinan. Namun, fakta ini tidak semata-mata terjadi di industri humas, melainkan di hampir semua industri.Tujuan dari artikel ini adalah untuk menganalisa permasalahan yang ada pada proses perekrutan praktisi hubungan masyarakat (humas) dalam sudut pandang praktisi senior. Untuk mencapai tujuan ini maka diadakan diskusi kelompok terarah dengan praktisi senior humas yang tergabung dalam sebuah asosiai profesi humas sebagai peserta. Data yang diperoleh dianalisa dari sudut pandang teori feminis dan velvet ghetto. Berdasarkan diskusi tersebut dapat diambil dua kesimpulan. Pertama, Bahwa profesi humas adalah 'profesi terbuka', yang berarti, a) baik pria dan perempuan, b) tanpa batasan usia, c) dari latar belakang dan disiplin apapun, tidak hanya komunikasi yang bisa memasuki profesi humas. Kedua, Bahwa secara statistik dan secara universal a) pendidikan humas lebih banyak memikat perempuan daripada laki-laki, b) perempuan praktisi humas jumlahnya melebihi praktisi pria, tetapi c) posisi-posisi senior, pada posisi top pada perusahaan-
\end{abstract}


perusahaan besar, baik itu nasional atau internasional, didominasi oleh praktisi pria. Penulis menyimpulkan bahwa perlu adanya upaya untuk meningkatkan derajat profesi humas di mata masyarakat, dan juga mengupayakan agar adanya keseteraan gender dalam meniti karir humas sampai ke tingkat top management. Penulis mengusulkan adanya kerjasama antara tiga pihak yaitu instansi pendidikan tinggi, asosiasi profesi, dan industri. Kerjasama tersebut dapat berupa mentorship antara praktisi pemula dengan praktisi manager; konseling karir; dan loka karya. Perusahaan juga dihimbau untuk memberlakukan kebijakan yang memudahkan perempuan untuk berkarir, seperti flextime dan pengadaan penitipan anak (daycare).

Kata Kunci: hubungan masyarakat, velvet ghetto, teori feminis

\section{Pendahuluan}

Industri komunikasi, yang mencakup profesional hubungan masyarakat (humas), pemasaran, dan periklanan acap kali dianggap sebagai industri feminin, hal ini karena jumlah peminat bidang komunikasi - baik di pendidikan ataupun industri - adalah perempuan, sehingga memberi kesan bahwa dalam industri komunikasi tidak ada diskriminasi gender terhadap perempuan. Namun, berbagai penelitian menunjukkan bahwa dengan sejalannya waktu, feminisasi sebuah industri berdampak negatif terhadap status dan remunerasi. Kenyataannya adalah tingkat top management industri komunikasi tetap didominasi oleh laki-laki.

Alasan mengapa profesi humas didominasi oleh perempuan (dalam segi jumlah) telah diteliti oleh Grunig, Toth, dan Hon (2001) dengan melakukan wawancara dengan praktisi-praktisi muda, dan menyimpulkan bahwa perempuan tertarik dengan industri komunikasi karena tidak terdapat hambatan-hambatan yang terlalu sulit untuk mencapai status profesional. Remunerasi yang ditawarkan oleh industri ini juga relatif lebih baik daripada banyak karir lain yang dipilih oleh perempuan, terutama pada posisi yang tidak memerlukan pengalaman. Secara umum perempuan menghargai fleksibilitas dalam pengaturan kerja, dan merasa bahwa prospek promosi terlihat menjanjikan. Industri komunikasi juga menarik karena keterampilan feminin tradisional dalam komunikasi - empati, jaringan, dan multi-tasking - didukung dan dihargai. Namun, kompetensi perempuan di bidangbidang tersebut juga dipandang sebelah mata dan dieksploitasi. Perempuan diharapkan untuk melakukan "pekerjaan emosional" seperti mendengarkan, membimbing, melayani, menghadapi orang-orang yang menyusahkan, dan bahkan membersihkan kekacauan literal dan figuratif (Probert, 1997).

Profesor dari Jerman, Romy Fröhlich, juga telah melakukan penelitian ekstensif tentang perempuan dalam profesi jurnalisme dan hubungan masyarakat. Fröhlich (2004) mengatakan bahwa perempuan kerap kali masuk dalam "jebakan keramahan" (friendliness trap) di mana sifat-sifat yang dianggap feminin membuka pintu untuk pekerjaan-pekerjaan yang tidak membutuhkan pengalaman, tapi sifat-sifat ini juga yang kemudian menjadi tidak menguntungkan saat perempuan ingin mendapatkan promosi, karena karakteristik perempuan seperti empati, perhatian, kebutuhan untuk mencapai konsensus, bakat untuk berurusan dengan orang, dan kemampuan untuk bekerja dalam atmosfer yang berorientasi tim. Semua karakteristik tersebut dianggap sebagai kualitas yang dapat digunakan 
sebagai keunggulan dalam berkarir, berbeda dengan karakteristik tipikal laki-laki yang khas seperti rasionalitas, kompetitif, keagresifan, dan individualisme.

Tujuan dari artikel ini adalah untuk menganalisa permasalahan yang ada pada proses perekrutan praktisi humas dalam sudut pandang praktisi senior. Untuk mencapai tujuan ini maka diadakan diskusi kelompok terarah dengan praktisi senior humas yang tergabung dalam sebuah asosiasi profesi humas sebagai peserta. Hasil diskusi kemudian dianalisa dari sudut pandang konsep gender dan velvet ghetto.

Salah satu pokok permasalahan yang ditemukan dalam studi gender humas adalah sedikitnya perempuan yang memegang peran kepemimpinan. Namun, fakta ini tidak semata-mata terjadi di industri humas, melainkan di hampir semua industri. Hal ini disebut sebagai fenomena langit-langit kaca (glass ceiling), yang merupakan penghalang tak terlihat yang mencegah perempuan dan minoritas lainnya bergerak ke dalam jajaran yang lebih tinggi dalam sebuah organisasi. (Dozier, 1988)

Banyak penelitian menggunakan perspektif feminis liberal yang memperjuangkan pemberdayaan perempuan untuk mengejar karir setinggi mungkin. Di sisi lain, perspektif feminis radikal percaya bahwa ketidaksetaraan gender yang bersifat struktural hanya dapat diberantas dengan menangani akar dari permasalahan tersebut, yaitu budaya masyarakat dan/atau budaya organisasi tersebut.

Penelitian komprehensif pertama bertema gender dalam industri hubungan masyarakat, berjudul The Velvet Ghetto (Cline, Masel-Walters, Toth, Turk, Smith, \& Johnson). Studi ini menemukan bahwa salah satu dampak dari fenomena velvet ghetto adalah bahwa meskipun perempuan telah puluhan tahun mendominasi industri humas, gaji perempuan masih jauh lebih rendah dibandingkan laki-laki (Taff, 2003). Sejak penelitian ini diterbitkan pada tahun 1986, banyak penelitian lain yang menyelidiki masalah gender yang menjelaskan status perempuan di industri humas, dengan menerapkan perspektif teori feminis (Toth, 2001).

Dari sudut pandang feminis liberal, studi velvet ghetto menyarankan agar perempuan meningkatkan kesadarannya terhadap ketidaksetaraan gender dalam hubungan masyarakat. Perempuan harus berusaha mencapai kesetaraan dan meningkatkan kemampuan dalam bernegosiasi remunerasi perempuan. Selanjutnya, program mentoring harus dikembangkan untuk membantu perempuan dalam mendapatkan pengalaman manajemen. Perempuan harus proaktif dalam mencari figur panutan untuk membantu mereka untuk maju (Toth, 1989). Namun, dari sudut pandang feminis radikal, solusi seharusnya tidak terkonsentrasi pada individu praktisi humas, melainkan pada perubahan dalam sistem patriarkal yang berpusat pada laki-laki (Rakow, 1989).

Hubungan masyarakat adalah kegiatan manajemen strategis yang membantu mengamankan fungsi jangka panjang suatu organisasi dalam masyarakat, dan untuk itu diperlukan spesialis pada tingkat manajerial, misalnya, manajer komunikasi, bukan teknisi komunikasi (Dozier, 1988). Industri komunikasi sering digambarkan sebagai velvet ghetto karena tidak adanya mobilitas ke jenjang atas dalam struktur perusahaan, sehingga penghuni suatu velvet ghetto kerap harus bergerak menyamping dalam ghetto serupa di 
perusahaan sejenis. Penghuni ghetto (pemukiman kumuh) harus berpindah dari satu pekerjaan buntu yang lain, dengan peningkatan gaji yang sangat kecil, itupun jika ada. Kesempatan kerja yang nyata baru muncul ketika seseorang pensiun, atau bergerak sama sekali di luar sistem perusahaan dan meninggalkan kekosongan (Scollard, 1995).

Gersh (1986) menyatakan, berdasarkan temuan dari studi Velvet Ghetto, perempuan kerap diasumsikan sebagai manajer yang tidak efektif. Hon et al (2001) juga setuju bahwa, meskipun peran teknis mungkin relatif fana bagi banyak praktisi pria, tampaknya hal tersebut relatif permanen bagi banyak perempuan. Jika fenomena ini memang ada, maka posisi top management suatu organisasi menjadi tidak terjangkau perempuan.

\section{Metode Penelitian}

Untuk menjawab rumusuan masalah, maka penelitian ini menggunakan metode Diskusi Kelompok Terarah (FGD) dengan pendekatan kualitatif. Grup milis, forum berita, dan asosiasi merupakan titik fokal untuk diskusi, pertukaran informasi dan tempat pengembangan profesional. Portal riset yang cerdas, suatu grup milis, forum berita atau asosiasi bisa juga dijadikan suatu titik bertemu bagi para pakar. Karenanya, Penulis memutuskan untuk mendiskusikan topik perekrutan praktisi humas dengan para anggota grup milis suatu asosiasi profesi humas yang terkemuka di Indonesia (anonim, atas permintaan peserta FGD).

Penulis meminta ijin melalui milis asosiasi tersebut untuk melakukan diskusi, dan kemudian mendapat 20 narasumber, yang kemudian dibagi menjadi dua grup, namun kedua grup memiliki ciri-ciri yang serupa. Narasumber yang dipilih adalah praktisi senior, dangan rata-rata pengalaman 20 tahun di bidang humas sehingga dianggap sangat memahami perkembangan dan kondisi industri humas di Indonesia; dan merupakan peserta aktif dalam grup milis tersebut.

Diskusi ini seputar iklan lowongan kerja yang baru terbit, untuk posisi public relations officer oleh sebuah perusahaan ritel besar di Jawa Timur. Iklan lowongan tersebut mensyaratkan hal-hal berikut:

1. Memiliki 2 tahun pengalaman kerja di bidang yang sama pada pusat perbelanjaan terkemuka (khususnya di Jakarta).

2. Perempuan, maksimal 30 tahun.

3. Berpenampilan menarik.

4. Fasih bahasa Inggris, baik lisan \& tertulis.

5. Kreatif, energetik, bisa bekerja dalam tim (team player) dan dapat belajar dengan cepat (fast learner).

6. Memiliki jaringan luas dengan media lokal dan nasional.

7. Memiliki keahlian dalam membangun jaringan sosial.

8. Memahami internet \& kanal promosi media lainnya.

9. Memiliki pemahaman yang baik tentang manajemen loyalitas pelanggan.

Iklan tersebut kemudian ditutup dengan informasi batas waktu para kandidat untuk mengirimkan curriculum vitae terbaru, surat lamaran dan foto terbaru. 
Iklan lowongan beserta syarat-syarat di atas sangat umum ditemukan sehingga dirasakan cukup mewakili iklan lowongan posisi humas pada umumnya. Para peserta diskusi kelompok terarah kemudian diminta untuk memberikan tanggapannya mengenai iklan di atas, dan membahas permasalahan-permasalahan yang ada dalam proses perekrutan praktisi humas, terutama dari sudut pandang gender. Berikut adalah hasil dari kedua diskusi kelompok terarah dan sejumlah kutipan dari para narasumber (inisial merupakan identitas dari para nara sumber).

\section{Hasil Penemuan dan Diskusi}

Peserta diskusi kelompok terarah memberikan tanggapan dengan mendiskusikan opini mengenai persepsi orang-orang mengenai profesi humas, secara khusus mengenai gender.

"Praktisi PR harus berhati-hati dengan iklan-iklan dengan bias seperti itu. Tidak ada yang salah dengan merekrut staff PR, tapi dengan melihat persyaratannya, orang akan bertanya, tipe pekerjaan PR apakah yang akan dilakukan di perusahaan tersebut? Dari dua persyaratan pertama, dapat disimpulkan kalau persepsi [pemberi kerja] akan public relations adalah perempuan yang muda dan menarik" (RNB).

Memang, banyak peserta yang setuju bahwa paradigma ini adalah mispersepsi mengenai profesi humas, dan walau secara fakta mayoritas praktisipraktisi di dunia humas adalah perempuan, banyak juga pakar humas yang pria.

"Pandangan bias tentang humas yang digambarkan dengan perempuan muda dan menarik telah lama diupayakan untuk dihilangkan. [Asosiasi ini] dan praktisi-praktisi, ahli-ahli, begitu juga akademisi PR dan komunikasi memiliki beberapa forum yang menggalakkan kampanye aliran pemikiran PR strategis. Bukan hanya PR dalam pengertian perempuan muda (maksimum 30 tahun), berpenampilan menarik, yang mendapatkan manikur dan pedikur, wangi, memberikan janji-janji besar tanpa maksud untuk menepatinya, dsb... Tidak salah untuk menjadi menarik, wangi, and muda, tetapi bila hal-hal tesebut dikategorikan sebagai persyaratan, kita bisa melihat dibalik itu ada diskriminasi” (RNB).

Nampaknya, banyak yang mengklaim bahwa paradigma ini telah tertanam sejak dari masa dari pendidikan di bangku kuliah:

"Waktu saya kuliah, teman-teman saya menertawai saya karena memilih manajemen humas sebagai konsentrasi studi karena saya adalah seorang pria. Pada waktu itu banyak teman saya yang memandang bahwa profesi humas hanya pantas untuk perempuan yang cantik dan suka bicara...menarik, lebih tepatnya, dan status sosial seseorang bahkan bisa naik bila bekerja di PR, sulit dipercaya...Yang lebih parah lagi adalah teman-teman aktivis saya mengatakan bahwa PR adalah salah satu pilar kapitalisme, walaupun kelompok-kelompok aktivis dan kelompok nonnirlaba juga menjalankan fungsi PR" (AA). 
“Waktu kuliah, dosen saya yang adalah orang asing mengatakan alasan kenapa banyak mahasiswa PR di Indonesa yang adalah perempuan, walaupun negara-negara yang lebih berkembang PR nya di dominasi oleh pria adalah karena PR di Indonesia adalah gugus depan. Tetapi kalau sudah menyangkut hal-hal yang strategis dan manajerial, pria lebih disukai, karena pria tidak mudah dipengaruhi oleh emosi” (PT).

Dapat dilihat dari kutipan di atas bahwa pekerjaan yang sifatnya teknis dan non-strategis dikaitkan dengan perempuan, sedangkan pekerjaan yang sifatnya manajerial dan strategis dikaitkan dengan pria. Walaupun banyak peserta yang setuju bahwa pria dan perempuan sama-sama kompeten dalam segala aspek profesi humas, namun ada juga, karena miskonsepsi yang populer tentang humas, lebih memilih praktisi pria bila dibandingkan praktisi perempuan. Satu praktisi pria mengatakan,

"Saya lebih memilih praktisi humas yang pria karena perempuan cenderung bergerak ke arah prilaku yang negatif. Saya melihat kenapa banyak perusahaan lebih cenderung mempekerjaan praktisi humas yang adalah perempuan menarik, menggunakan rok yang sangat pendek. Itu yang disebut sebagai eksploitasi, khususnya bila mereka memiliki pacar atau suami, saya merasa kasihan untuk pacar atau suami yang sering ditinggalkan di rumah karena pekerjaan PR mereka" (JD).

Di sini, budaya patriarki terlihat sangat jelas, perempuan tidak hanya disalahkan dalam 'bergerak ke arah prilaku yang negatif,' tetapi peserta juga merasa 'kasihan karena suami atau pacar sering ditinggalkan di rumah' supaya perempuan bisa bekerja, namun tidak satupun peserta yang merasa kasihan dengan istri atau pacar yang ditinggalkan di rumah oleh praktisi pria.

Meskipun demikian, seperti wawancara dengan para peserta, tampaknya peserta grup milis pada umumnya datang dari perspektif feminisme liberal, yang memiliki karakteristik penekanan pada individualisme atas dasar kesetaraan. Berdasarkan filosofi ini, masyarakat sendiri tidak memerlukan perbaikan yang mendasar; sebaliknya, hukum lah yang harusnya diubah, dan harusnya diciptakan kesempatan agar perempuan dapat menjadi setara di masyarakat. Seorang peserta perempuan mengatakan,

"Satu hal yang saya percaya adalah, emansipasi perempuan, termasuk dalam humas, akan sukses bila pria dan perempuan saling menghormati eksistensinya sebagai manusia: Perempuan dengan segala sifat feminimnya yang alamiah, dan pria dengan maskulinitasnya yang alamiah. Saya tidak pernah mencoba menjadi lebih dari diri saya" (AM).

Memang, feminisme liberal menyarankan manfaat dari psikologi androgini, dengan menciptakan masyarat yang buta gender untuk memberikan kesempatan yang setara bagi pria dan perempuan. Dalam diskusi ini, ada beberapa peserta yang menyarakan seorang public relations officer yang androgini akan ideal, 
"Dalam observasi saya, semakin tinggi suatu posisi, maka semakin praktisi PR tersebut diharapkan memiliki sifat maskulin, karena posisi tersebut mensyaratkan seseorang untuk bertindak independen dalam mengambil keputusan strategis...Perempuan yang feminin cenderung lemah and mudah dirayu. Pria, yang sangat macho, cenderung mudah marah. Perempuan yang agresif cenderung mengintimidasi klien-klien. Sepertinya yang paling baik adalah praktisi perempuan yang maskulin, dan pria yang feminin. Karena Anda harus selalu tersenyum saat terjadi krisis. Sedangkan, perempuan harus menjadi figur yang kuat, bukan figur yang lemah dan feminim yang umumnya sangat lambat, dan menangis dalam keadaan krisis" (EGA).

Namun demikian, ada juga beberapa narasumber yang tidak melihat adanya masalah dengan iklan lowongan yang demikian. Narasumber mengklaim telah melihat beberapa iklan lowongan serupa sebelumnya dan tidak melihat hal tersebut sebagai suatu ancaman bagi sektor humas, sebagaimana seorang praktisi humas senior berkata,

"Dalam pikiran saya, iklan lowongan tersebut bukan berarti menurunkan derajat humas...Setidaknya, untuk saya, yang kebetulan telah lahir sebelum kalian, rekan-rekan ku, dan telah berkesempatan untuk bekerja di PR lebih dari tiga dasawarsa. Ini bukan pertama kalinya saya melihat iklan lowongan seperti itu di Indonesia. Pernah satu satu kali saya memperhatikan iklan lowongan untuk posisi PR di suatu institusi. Ternyata apa yang mereka maksudkan adalah "perempuan perwakilan sales" untuk perusahaan investasi. Ada yang lebih buruk, di Hong Kong and kota-kota di Eropa Timur, klub malam dan kasino menyebut penerima tamu (hostess) mereka sebagai public relations. Saya yakin mereka tidak bermaksud untuk menurunkan derajat profesi public relations. Apa yang terjadi? Kesimpulan saya adalah mereka tidak mengetahui profesi PR yang sesungguhnya, sebagaimana kita tidak ingin mengetahui profesi broker asuransi, atau pedagang valuta asing. Film Amerika sering kali menurunkan derajat profesi PR dengan pernyataan-pernyataan seperti "Ah..itu hanya PR" untuk hal yang berbau promosi, propaganda dan halhal manipulatif yang lain. Karenanya, bahkan di Amerika dan seluruh dunia, profesi PR tidak dikenal seperti profesi-profesi lain seperti dokter, polisi, wartawan, dsb.” (TS).

Intinya, iklan-iklan lowongan praktisi humas seperti yang telah didiskusikan, tidak dianggap sebagai upaya untuk menjatuhkan derajat profesi humas, melainkan disebabkan atas ketidak-tahuan.

Pada akhirnya, secara keseluruhan, ada dua hal yang disepakati oleh para peserta group discussion ini:

1. Bahwa profesi humas adalah 'profesi terbuka', yang berarti, a) baik pria dan perempuan, b) tanpa batasan usia, c) dari latar belakang dan disiplin apapun, tidak hanya komunikasi yang bisa memasuki profesi Public Relations. 
Hal ini menganjurkan bahwa harus ada kesempatan yang setara untuk kedua gender tanpa batasan usia untuk memasuki profesi ini, dan penulis sangat mendukung pendapat ini. Namun, hal ini juga menandakan adanya encroachment di industri ini. Penulis menyayangkan pendapat ini yang berasal dari peserta, dan merasa bahwa encroachment tersebut akan mendukung lebih lanjut pandangan populer bahwa humas adalah pekerjaan yang mudah yang bisa dilakukan oleh siapapun, dan bahwa pendidikan humas tidak terlalu penting. Hal ini juga dapat menjadi penghalang bagi orang yang ingin serius mengejar karir di bidang humas, karena adanya pandangan bahwa pada akhirnya siapa saja dari bidang apa saja dapat memimpin bagian humas sebuah perusahaan atau organisasi. Hal ini juga dapat berdampak pada pandangan bahwa pendidikan formal di bidang humas juga tidak perlu.

2. Bahwa secara kuantitatif dan secara universal a) pendidikan humas lebih banyak memikat perempuan daripada laki-laki, b) perempuan praktisi humas jumlahnya melebihi praktisi pria, tetapi c) posisi-posisi senior, pada posisi top pada perusahaan-perusahaan besar, baik itu nasional atau internasional, didominasi oleh praktisi pria. Hal ini terefleksi dari keanggotaan IPRA, suatu organisasi untuk dunia profesi humas, dimana anggotanya (60-70\%) adalah pria baik itu praktisi senior, konsultan, dan pendidik humas.

Beberapa peserta menyarankan mengingat fakta posisi top management didominasi oleh pria bukan perempuan bisa jadi karena pria mengejar karir secara penuh, sedangkan perempuan, karena satu atau dua alasan, berhenti dari profesi di tengah jalan. Namun, para perserta, tidak menganggap bahwa hal tersebut dikarenakan batasan potensi perempuan:

"Kita praktisi PR tidak bisa menyalahkan orang lain atas paradigma bahwa PR adalah bagian dari bauran pemasaran, karena praktisi PR sendiri, dalam melakukan pekerjaan mereka, suka dan merasa nyaman dengan posisi teknis seperti publisitas, propaganda, relasi media, publikasi internal, dsb. Dalam menjalankan program-program PR, praktisi-praktisi jarang mengikuti yang disebut oleh McNamara sebagai Model SPIE: Strategic research (riset strategis), Planning (perencanaan), Implementation (implementasi), dan Evaluation (evaluasi). Kurangnya evaluasi dalam public relations membuat pekerjaan PR tidak berwujud di mata CEO" (RNB).

Temuan dari diskusi grup ini telah memberikan informasi yang diperlukan yang tidak dapat ditemukan dalam literatur-literatur. Terlebih, penemuan tersebut menyokong pendapat bahwa bias gender ada dalam proses rekrutmen (sebagaimana iklan yang didiskusikan dalam grup hanyalah satu dari banyak iklan lowongan yang ditemukan pada media di Indonesia), dan banyak perusahaan yang akan mencari perempuan yang menarik sebagai praktisi humas untuk 'gugus depan' ketimbang komunikator yang kompeten. 
Seperti praktisi perempuan dalam studi ini, tidak mengeluh tentang diskriminasi gender atau ketidakmampuan untuk naik ke tingkat manajerial. Praktisi perempuan sepertinya tidak memiliki masalah dengan sistem patriaki di Indonesia, dan menerima peran tugas utamanya sebagai ibu dan istri. Tugas sebagai pencari nafkah di keluarga tetap dipegang pria, sehingga karir perempuan adalah yang kedua setelah pria. Seorang Account Executive perempuan mengatakan,

"Saya punya keluarga, saya memiliki dua anak kecil, saya lebih suka bekerja dari rumah sebagai freelancer... Saya tidak memiliki ambisi untuk mencapai paling atas disini. Pada akhirnya, Saya lebih suka tinggal di rumah dan punya usaha sendiri."

Namun, praktisi perempuan lebih terganggu dengan persepsi publik tentang pekerjaan humas, yang mengakibatkan derajatnya menurun sebagai seorang profesional dan rusaknya image perempuan. Karena diskriminasi dapat menyebabkan berkurangnya kesempatan dan potensi untuk menjadi lebih baik dan kompeten diantara para praktisi. Dengan melabel humas sebagai profesi perempuan, hal tersebut juga dapat membatasi peran para praktisi hanya pada level teknis, yang adalah lawan dari posisi manajerial, termasuk mengucilkan mereka dari koalisi dominan.

\section{Simpulan}

Artikel ini menganalisa permasalahan yang ada pada proses perekrutan praktisi hubungan masyarakat menurut sudut pandang praktisi senior. Berdasarkan diskusi kelompok terarah (FGD) dengan praktisi senior humas, dapat diambil dua kesimpulan:

1. Bahwa profesi humas adalah 'profesi terbuka', yang berarti, a) baik pria dan perempuan, b) tanpa batasan usia, c) dari latar belakang dan disiplin apapun, tidak hanya komunikasi yang bisa memasuki profesi humas.

2. Bahwa secara kuantitatif dan secara universal a) pendidikan humas lebih banyak memikat perempuan daripada laki-laki, b) perempuan praktisi humas jumlahnya melebihi praktisi pria, tetapi c) posisi-posisi senior, pada posisi top pada perusahaan-perusahaan besar, baik itu nasional atau internasional, didominasi oleh praktisi pria.

Asumsi bahwa humas sebagai profesi perempuan dapat memberikan reputasi buruk bagi industri dan praktisinya karena persepsi negatif orang Indonesia yang mengkaitkan praktisi humas sebagai perempuan menarik yang hanya melayani sebagai pemanis untuk menemani boss-boss dan klien-klien perusahaan mereka. Dengan demikian, praktisi harus berjuang untuk legitimasi dan pengakuan.

Ada kebutuhan riset yang sadar gender tentang remunerasi dan jenjang karir di industri humas di Indonesia. Karena selain studi oleh Grunig, Toth dan Hon, yang berjudul Women in Public Relations: How Gender Influences Practice (2001), belum banyak riset yang signifikan dan komprehensif tentang gender di 
industri humas, penemuan mereka memberikan titik pangkal perbandingan yang berguna untuk penelusuran di Indonesia. Sembari mengakui bahwa industri di Amerika Serikat lebih besar dan memiliki sejarah yang lebih panjang, faktorfaktor ini juga berarti bahwa industri di Amerika Serikat mempengaruhi perkembangan dan praktik Industri di Indonesia. Analisis gender atas pasar tenaga kerja Indonesia dan Amerika Serikat juga akan berguna bila diperbandingan, sembari mempertimbangkan sejarah dan konteks kebijakan yang berbeda.

Penulis percaya ada perbedaan antara pria dan perempuan, tidak hanya didasarkan pada ciri biologis, tetapi juga pada orientasi peran gender yang memprediksi perilaku. Namun, penulis juga berpendapat bahwa stereotip sosial telah mendorong jauh perbedaan yang berlebihan. Perempuan memiliki atribut dan kemampuan yang membantu organisasinya, sama seperti laki-laki. Namun demikian, perempuan telah dibatasi dalam ekspektasi-ekspektasi sosial tertentu. Akibatnya, industri komunikasi telah diberi label sebagai lapangan dengan terlalu banyak perempuan, seolah-olah perempuan tidak bisa memberikan kontribusi cukup untuk bidang komunikasi, dan seolah-olah hanya laki-laki yang bisa mengisi unsur yang hilang pada industri komunikasi. Tidak diragukan lagi, pria membawa perspektif yang signifikan dalam bidang komunikasi, tetapi masyarakat sering memposisikan laki-laki lebih berharga daripada perempuan dan dengan demikian mendiskreditkan perempuan, dan sebagai akibatnya, industri komunikasi tersebut secara keseluruhan.

Untuk menyiasati encroachment dan meningkatkan derajat profesi humas di kalangan masyarakat, Penulis menyarankan adanya insentif untuk memperoleh sertifikasi bagi praktisi humas. Sekarang ini masih sedikit lembaga sertifikasi di bidang kehumasan, terutama karena perusahaan pemberi kerja tidak menyaratkan sertifikasi bagi pegawainya. Perusahaan juga dihimbau untuk mengadakan program mentorship, terutama bagi praktisi muda perempuan, sehingga dari awal karirnya, perempuan sudah memiliki role model yang dapat menginspirasi perempuan untuk serius meniti karir di bidang humas. Program pelatihan dan konseling karir juga dapat diadakan secara berkala oleh perusahaan, sehingga di setiap jenjang karirnya, para praktisi dapat memutakhirkan pengetahuannya di bidang humas. Untuk ini, sangat diperlukan adanya kolaborasi antara perusahaan dengan asosiasi profesi humas dan juga instansi pendidikan tinggi / universitas. Selain itu, untuk mengupayakan kesetaraan gender di mana baik pratisi humas perempuan maupun laki-laki dapat meniti karirnya hingga ke jenjang top management, maka perusahaan dihimbau untuk memberi opsi yang tidak akan menghalangi pegawai perempuan yang sudah berkeluarga untuk tetap meniti karir. Opsi tersebut dapat berupa flextime, cuti baik untuk perempuan yang baru melahirkan maupun utuk pria yang istrinya baru melahirkan (sehingga dapat turut memikul tanggung jawab sebagai orang tua), dan penyediaan instansi penitipan anak (daycare) bagi pegawai yang mempunyai anak kecil.

\section{Ucapan Terima Kasih}

Penulis mengucapkan terima kasih kepada para praktisi senior humas yang telah menyediakan waktunya untuk berpartisipasi dalam penelitian ini. 


\section{Daftar Pustaka}

Dozier, D. (1988). Breaking public relations' glass ceiling. Public Relations Review, 14, 6-14.

Fröhlich, R. (2004). Feminine and feminist values in communication professions: Exceptional skills and expertise or 'friendliness trap'? In M. de Bruin and K. Ross (Eds.), Gender \& newsroom cultures: Industries at work (pp. 6780). Cresskill, NJ: Hampton Press.

Gersh, D. (1986). There are more women in public relations, but inequality still exists. Editor and Publisher, 19, 78.

Grunig, L., Toth, E., \& Hon, L. (2001). Women in public relations: How gender influences practice. New York: The Guilford Press.

Hon., L., Grunig, L., \& Toth, E. (2001). Women in public relations: How gender influences practice. New York, NY: Guilford.

Probert, B. (1997). Women's working lives. In Hughes, K. (Ed). Contemporary Australian Feminism. Melbourne: Longman.

Rakow, L. F. (1989). From the feminization of public relations to the promise of feminism. Beyond the velvet ghetto, 287-298.

Scollard, J.R. (1995). Escape from the Velvet Ghetto. The Public Relations Strategist (Summer).

Taff, H. P. (2003). Times Have Changed? IABC Research Foundation'sThe Velvet Ghetto'study Revisited. COMMUNICATION WORLD-SAN FRANCISCO-, 20(2), 10-11.

Toth, E. L. (1989). Whose Freedom and Equity in Public Relations? The Gender Balance Argument.

Toth, E. L. (2001). How feminist theory advanced the practice of public relations. Handbook of public relations, 237-246. 